\title{
Sclerosing haemangioma of the lung: A case report
}

Thapa $\mathbf{R}^{\mathbf{1}}$, Lakhey $\mathbf{M}^{2}$, Shrestha $\mathbf{U}^{3}$

${ }^{1}$ Lecturer, ${ }^{2}$ Professor, Department of Pathology, Kathmandu Medical College Teaching Hospital, Kathmandu, Nepal ${ }^{3}$ Medicare National Hospital and Research Centre, Kathmandu, Nepal

\section{Abstract}

Sclerosing haemangioma is a rare neoplasm of the lung which behaves in a clinically benign fashion. Herein, a case of sclerosing haemangioma of the lung in a 52 years old woman is reported. She presented with symptoms of cough and chest pain. Chest X - ray and CT scan showed a well - defined lesion in lower lobe of left lung. Bronchoscopic biopsy findings were suggestive of a carcinoid tumor. Later the tumor was removed by lobectomy. The distinctive constellation of histologic findings revealed it to be a sclerosing haemangioma.

Key words: Bronchoscopic biopsy, Carcinoid tumor, Immunohistochemistry, Sclerosing haemangioma

\section{Introduction}

clerosing haemangioma $(\mathrm{SH})$ is a rare benign lung Oneoplasm that was first described by Liebow and Hubbell in 1956. They defined pulmonary fibrosing haemangioma as a marked vascular proliferation with a tendency to fibrosis, and associated with papillary vegetation, extensive histiocytic infiltration and haemorrhage at various stages of organization'1. This tumor was originally thought to be a lesion derived from vascular structures due to its rich content of blood vessels. However, immunohistochemical analysis showed clear evidence that $\mathrm{SH}$ is derived from primitive respiratory epithelium (immature type 2 pneumocytes). Hence the designation 'Benign Fibrosing Pneumocytoma' seems to be more appropriate ${ }^{2}$. The tumor shows a marked female predilection and is more common in the fourth to fifth decades of life ${ }^{3}$. Herein, we report a case of sclerosing haemangioma of the lung in a 52 year old female.

\section{Case Report}

A 52 year old female presented with two months history of dry cough on and off associated with mild chest pain. There was no history of fever and weight loss. On general physical examination, there was decreased respiratory sounds in the left lower chest. Chest $X$ - ray showed a well - defined opacification in the left lower lobe (Figure
1) On CT scan of chest- plain and I.V. contrast, a welldefined sharply marginated homogenous hypodense soft tissue mass measuring 57 x $56 \mathrm{~mm}$ noted in apical segment of left lung lower lobe was seen (Figure 2). Histology of the tumour could not be determined clearly on the tiny bronchoscopic biopsy. A suggestion of carcinoid tumour was however made. Left lower lobectomy was done and the specimen was sent for histopathological evaluation.

Grossly, a mass was identified on the upper anterior portion measuring $6 \mathrm{~cm}$ in diameter. Cut surface was well circumscribed, solid, greyish white with areas of haemorrhage (Figure 3). Microscopic examination revealed a tumour with papillary, sclerotic, solid and haemorrhagic patterns (Figure 4). Two cell types were seen, round stromal cells and surface cells. Round cells were small, uniform with bland oval nuclei. Complex papillae lined by cuboidal cells were observed. The stalk contained round cells and was mostly sclerotic. Focal atypia was observed in the cells. Intranuclear inclusion was also observed. Large blood filled spaces lined by epithelial cells, foci of haemorrhage, haemosiderin laden macrophages, xanthoma cells, cholesterol clefts and psammoma bodies were also present. The adjacent lung parenchyma was compressed.

\footnotetext{
Address for correspondence

Dr. Rupendra Thapa

Lecturer, Department of Pathology

Kathmandu Medical College Teaching Hospital

Kathmandu, Nepal

E-mail: rup432@gmail.com
} 


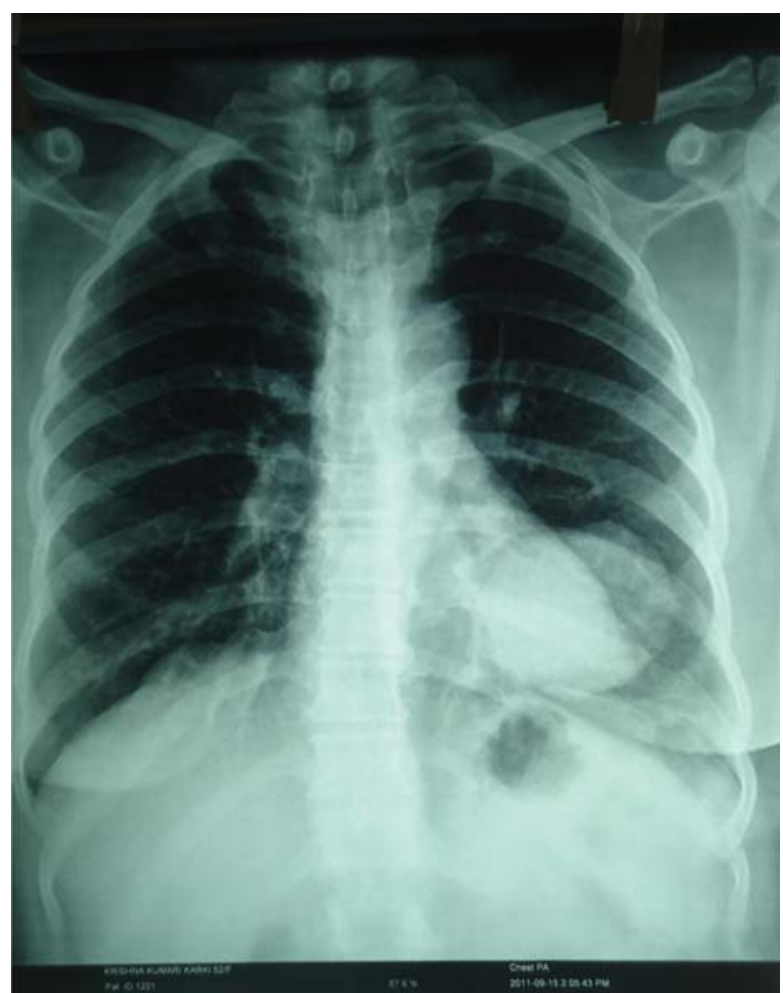

Fig. 1: Chest X-ray showing a well - defined opacification in the left lower lobe

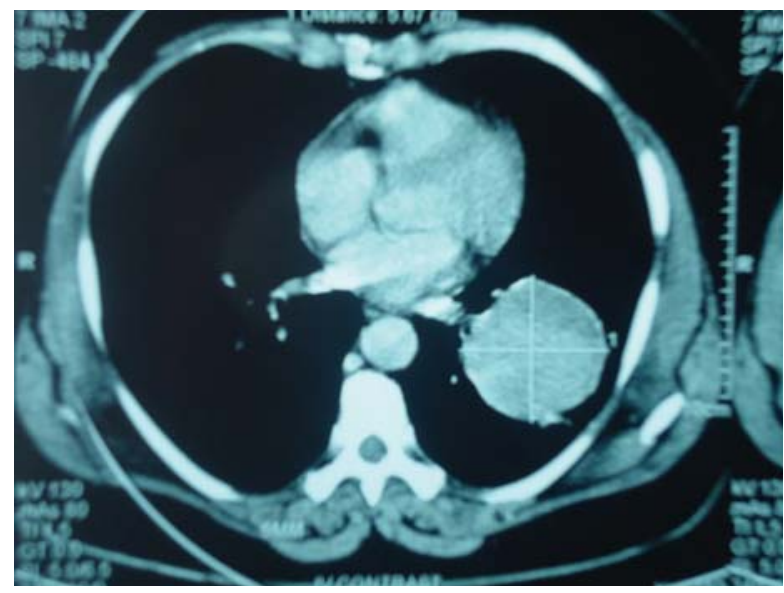

Fig. 2: CT scan of chest I.V. contrast

\section{Discussion}

Sclerosing haemangioma is a rare lung tumour without a definite classification. It is rare in western countries but in East Asia the frequency is as high as carcinoid tumor $^{4}$. In a series of 45 benign neoplasms, Sugio et al. found 10 tumours to be sclerosing haemangioma, the second most common benign tumour after hamartochondroma ${ }^{3}$. It affects middle aged adults with a female predominance $(80 \% \text { cases })^{5}$. Most tumours are solitary and peripheral; $4 \%$ of cases are multiple ${ }^{6}$. The

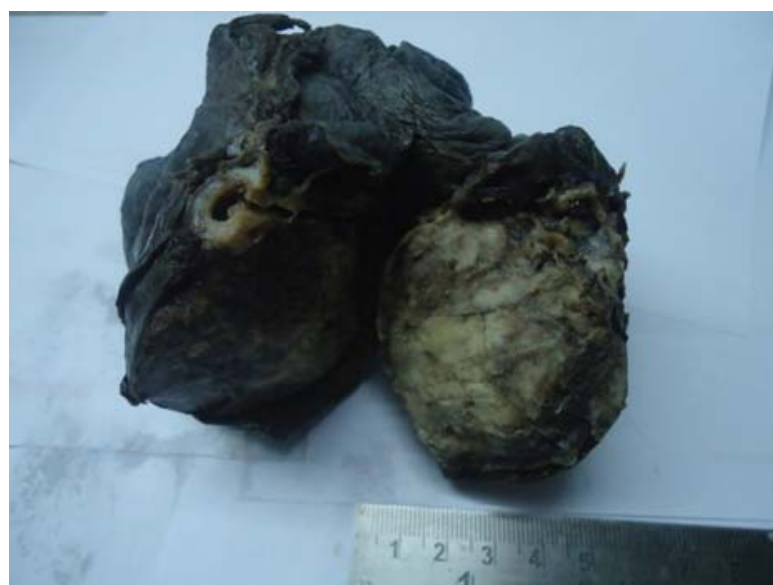

Fig. 3: Gross specimen showing well circumscribed mass.

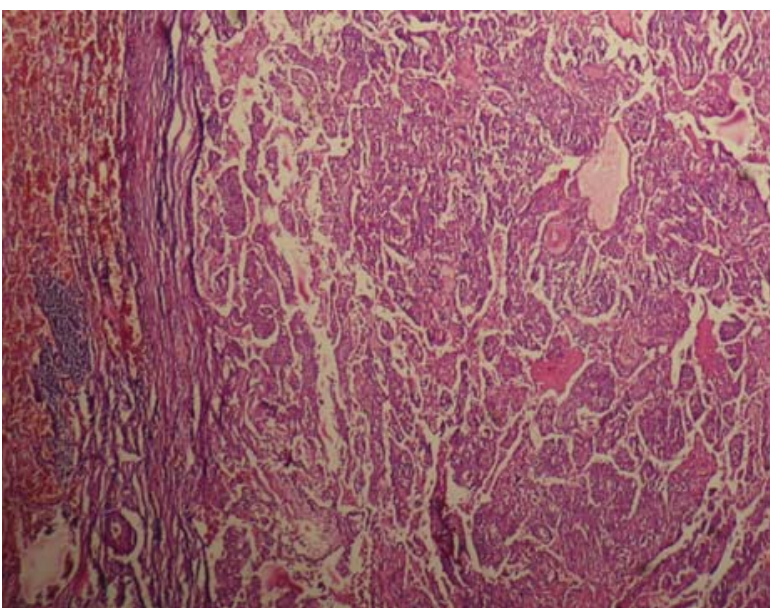

Fig.4: Tumor with papillary, sclerotic, solid and hemorrhagic patterns on low - power examination. ( HE stain, X100)

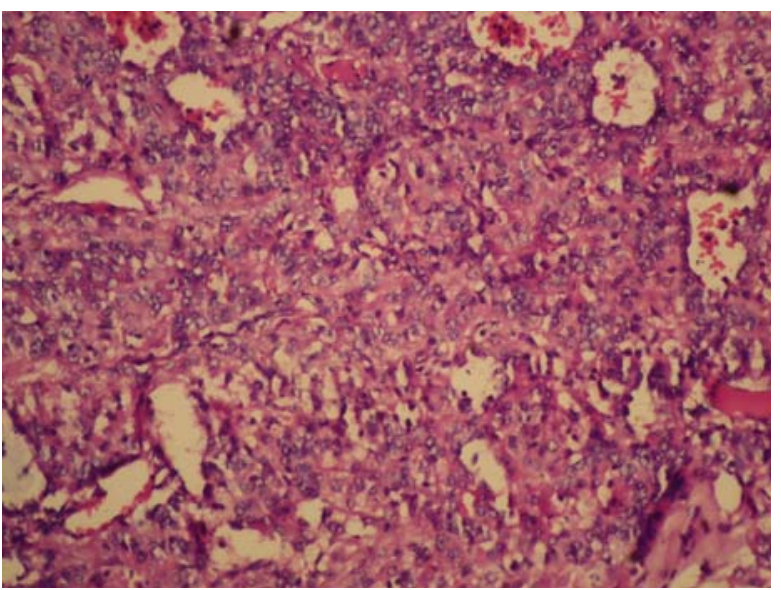

Fig. 5: Two cell types are seen, round stromal cells and surface cells. (HE stain, X400)

patients are mostly asymptomatic. The symptoms are usually due to compression of surrounding tissue. Our patient had presented with cough and chest pain for 
duration of two months. Chest $\mathrm{X}$ - ray reveals a solitary well-defined lesion. CT scan shows a circumscribed mass with marked contrast enhancement, foci of calcification and no infiltration of surrounding tissue. Due to its rich vasculature and prominent angiomatoid features this tumour was initially considered to be vascular in origin. Various other origins like epithelial, mesothelial, mesenchymal and neuroendocrine have been postulated ${ }^{4}$. Electron microscopic studies suggested either alveolar pneumocytes or mesothelium as the origin. Multiple authors utilizing immunologic studies have supported the hypothesis that both bronchioles and alveolar type 2 pneumocytes constitute simultaneously the cells of originin $2,7,8$. Immunohistochemistry suggests that sclerosing haemangioma is derived from primitive, undifferentiated respiratory epithelium. Round cells express Thyroid Transcription Factor-1 (TTF-1) and Epithelial Membrane Antigen (EMA), but are pancytokeratin negative. Surface cells express TTF - 1, EMA, pancytokeratin and surface apoprotein $\mathrm{A}^{4}$. Molecular studies demonstrated the same monoclonal pattern in both cell types proving it to be a true neoplasm and not a hamartoma'. Sclerosing haemangioma behaves in a clinically benign fashion and are considered low - grade neoplasm. No recurrence or disease-related deaths have been reported. They may spread to regional lymph nodes in approximately $1 \%$ of cases $^{5,10,11}$. Reported cases with hilar or mediastinal lymph node involvement do not have bad prognosis ${ }^{12,13}$. In a series of 4 patients with pulmonary sclerosing haemangioma with regional lymph node metastases, Miyagawa - Hayashino et. al found no recurrences or residual disease at a mean follow - up of 4.7 years (range, $2.3-10$ years) ${ }^{14}$.

Diagnosis may be difficult on bronchoscopic biopsies which are usually small and may miss the distinctive constellation of histologic features which are characteristic of this tumour. A mistaken diagnosis of glomus or carcinoid tumours can be made if there is predominance of the uniform bland stromal cells. Likewise sampling of limited papillary areas may be misdiagnosed as papillary pulmonary epithelial neoplasms. The presence of vacuolated and clear cells may be misdiagnosed as primary or metastatic clear cell tumours. Hence a wedge biopsy may be necessary for correct diagnosis. Isolated or solid nests of neuroendocrine cells may occur in sclerosing haemangioma. Sclerosing haemangioma combined with typical carcinoid tumours have been described.

\section{Conclusion}

Sclerosing haemangioma is a rare low - grade pulmonary neoplasm with a distinctive constellation of histologic findings. Diagnosis may be difficult on bronchoscopic biopsy. Immunohistochemistry confirms primitive, undifferentiated respiratory epithelium as cell of origin. Regional lymph node metastasis is known which does not affect prognosis.

\section{References}

1. Liebow AA, Hubbel DS. Sclerosing hemangioma (histiocytoma, xanthoma) of the lung. Cancer. 1956;9:53-75.

2. Gaucher L, Patra P, Despins $P$ et al. A rare tumor: benign sclerosing pneumocytoma with an intrascissural development. Poulmon Coeur. 1983;39(6):321-6.

3. Sugio K, Yokoyama H, Kaneko S et al. Sclerosing hemangioma of the lung:radiographic and pathological study. Ann Thorac Surg. 1992;53(2):295-300.

4. Devouassoux-Shisheboran $M$, Nicholson AG, Leslie K, Niho S. Sclerosing hemangioma. The WHO Classification of Tumors of the Lung, Pleura,Thymus and Heart. 2004;1:115-7.

5. Devouassoux-Shisheboran M, Hayashi T, Linnoila RI, Koss MN, Travis WD. A clinicopathologic study of 100 cases of pulmonary sclerosing hemangioma with immunohistochemical studies: TTF-1 is expressed in both round and surface cells, suggesting an origin

from primitive respiratory epithelium. Am J Surg Pathol. 2000;24:906-16.

6. Lee ST, Lee YC, Hsu CY, Lin CC. Bilateral multiple sclerosing hemangiomas of the lung. Chest. 1992;101:572-3.

7. Shimosato Y: Lung tumors of uncertain histogenesis. Semin Diag Pathol. 1995;12(2):185-92.

8. Yousem SA, Wick MR, Singh G, et al. Socalled sclerosing hemangioma of lung: An Immunohistochemical study supporting a respiratory epithelial origin. Am J Surg Pathol. 1988; 12(8):582-90.

9. Niho S, Suzuki K, Yokose T, Kodama T, Nishiwaki $\mathrm{Y}$, Esumi $\mathrm{H}$. Monoclonality of both pale cells and cuboidal cells of sclerosing hemangioma of the lung. Am J Pathol. 1998;152:1065-9.

10. Kim KH, Sul HJ, Kang DY. Sclerosing hemangioma with lymph node metastasis. Yonsei Med J. 2003; 44:150-4. 
11. Miyagawa-Hayashino A, Tazelaar HD, Langel DJ, Colby TV. Pulmonary clerosing hemangioma with lymph node metastases: report of 4 cases. Arch Pathol Lab Med. 2003;127:321-5.

12. Nicholson AG, Magkou C, Snead D, Vohra HA, Sheppard MN, Goldstraw P, Beddow E, Hansell DM, Travis WD, Corrin B. Unusual sclerosing haemangiomas and sclerosing haemangioma- like lesions, and the value of TTF-1 in making the diagnosis. Histopathology. 2002;41:404-13.

13. Yano M, Yamakawa Y, Kiriyama M, Hara M, Murase T. Sclerosing hemangioma with metastases to multiple nodal stations. Ann Thorac Surg. 2002;73:981-3.

14. Miyagawa - Hayashino A, Tazelaar HD, Langel DJ et al. Pulmonary sclerosing hemangioma with lymph node metastases : report of 4 cases. Arch Pathol Lab Med. 2003;127(3):321-5. 